\title{
Behcet's disease involved the root of aorta in the treatment with modified Bentall procedure: a case report
}

\author{
Zeyi Cheng, Zhefeng Kang, Yupeng Ji and Yingqiang Guo*
}

\begin{abstract}
Background: Behcet's disease (BD) is a multisystemic vasculitis of unknown etiology, the incidence of cardiovascular system involvement is rare, about1-5\% (Sakane et al., N Engl J Med 341:1284-91, 1999). BD combined with aortic pseudoaneurysm and aortic valve regurgitation is usually need surgical treatment, but there is controversy about which surgical method to choose.

Case presentation: We report a case of BD combined with severe aortic valve regurgitation and two giant pseudoaneurysms of the aortic sinus. The patient underwent modified Bentall procedure (MBP) and use oral immunosuppressive as well as corticosteroid strictly, after 8 months follow-up, the patient recovered well.

Conclusion: For patient with aortic valve regurgitation and ascend aortic pseudoaneurysm caused by BD, we recommend modified Bentall procedure when rheumatism in a stable period. Corticosteroids and immunosuppressive drugs should be used before and after surgery.
\end{abstract}

Keywords: Behcet's disease, Aortic valve regurgitation, Aortic sinus pseudoaneurysm, Bentall procedure

\section{Background}

$\mathrm{BD}$ is a systematic chronic vasculitis that involves multiple systems, but the mechanism of BD still unclear. The main clinical manifestations include oral ulcers, genital ulcers, ophthalmia, skin lesions, Vascular, gastrointestinal, neurological systems may be also involved. BD combined with aortic pseudoaneurysm and aortic valve regurgitation is rare, and in majority of cases usually died for vascular complications. we report a case of BD combined with aortic valve regurgitation and two giant pseudoaneurysms of the aortic sinus, the patient was successfully treated by modified Bentall procedure.

\section{Case presentation}

A-39-year old Chinese man was admitted to our hospital for repeated oral ulcers and headaches for 8 years, chest pain for 7 months. He had no diabetes, no relevant medical family history, and no external genital ulcer. The laboratory test results: C-reactive protein of

* Correspondence: drguoyq@hotmail.com

Department of Cardiovascular Surgery, West China Hospital, Sichuan

University, Chengdu, Sichuan 610041, People's Republic of China
$32.3 \mathrm{mg} / \mathrm{L}$ (normal value: $<5 \mathrm{mg} / \mathrm{L}$ ), anti-nuclear antibody (ANA) was positive (normal value: negative), ESR of $55 \mathrm{mg} / \mathrm{h}$ (normal value: male: 0-15 ml/h, female: 0$20 \mathrm{ml} / \mathrm{h}$ ). Transthoracic echocardiography (TTE) demonstrated: aortic sinus was $35 \times 57 \mathrm{~mm}$, ascending aorta diameter was $37 \mathrm{~mm}$, at the junction of right and left coronary sinus there was a $12 \times 14 \mathrm{~mm}$ cystic structure was formed outside from aortic wall, and a $40 \times 23 \mathrm{~mm}$ cystic structure was formed at the junction of orifice of coronary sinus, as shown in Fig. 1. CTA scan indicated that the aortic sinus was outwards, the large cross-section area about $4.4 \mathrm{~cm} \times 2.6 \mathrm{~cm}$, as shown in Fig. 2. After admission to the hospital, he was treated with Glucocorticoid, Thalidomide, and Atorvastatin in the rheumatic immunology department until the inflammatory markers returned to a normal level, then he received modified Bentall surgery and continue to take medicine as pre-operation. After 8 months follow-up, the patient recovered well: TTE indicated artificial blood vessel has no apparent abnormalities and artificial heart valve is functioning well, no perivalvular leakage (PVL), eject fraction is $62 \%$.

(c) The Author(s). 2020 Open Access This article is distributed under the terms of the Creative Commons Attribution 4.0 International License (http://creativecommons.org/licenses/by/4.0/), which permits unrestricted use, distribution, and reproduction in any medium, provided you give appropriate credit to the original author(s) and the source, provide a link to the Creative Commons license, and indicate if changes were made. The Creative Commons Public Domain Dedication waiver (http://creativecommons.org/publicdomain/zero/1.0/) applies to the data made available in this article, unless otherwise stated. 


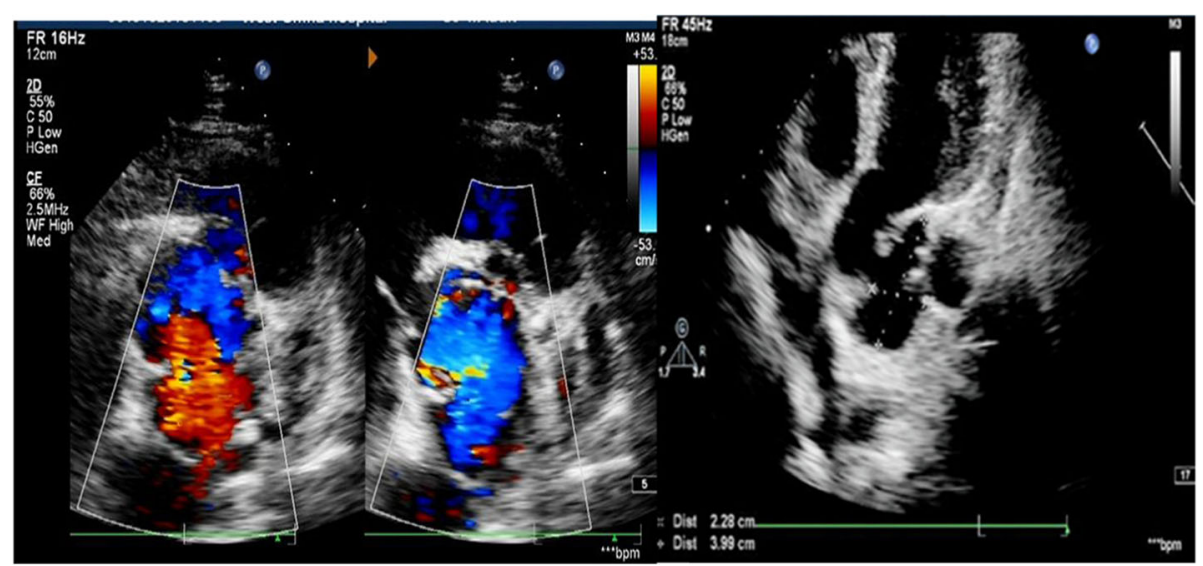

Fig. 1 TTE demonstrated aortic valve regurgitation, aortic sinus pseudoaneurysms

Surgery process: median sternotomy and establish total cardiopulmonary bypass (CPB), myocardial protection with cold blood cardioplegia. Open the ascend aorta, cut the brachiocephalic artery, the native root including the annulus was excised, aortic root replacement with the modified Bentall technique was performed: The valved conduit procedure was a modified Bentall operation where the aortic mechanical valve prosthesis was sutured into the graft at $1 \mathrm{~cm}$ from the end of the graft with a continuous 3-0 polypropylene suture, forming a composite graft, which was directly sutured to the left ventricular outflow tract with a continuous 3-0 polypropylene suture other than to annulus, and then the composite graft was fixed by outside the aortic wall with a belt-like Teflon felt. The coronary buttons were anastomosed to the composite valve graft end-to-side with continuous suture used a 5-0 polypropylene suture without any tension, at last, the distal end of the conduit was anastomosed to the distal ascending aorta with continuous 3-0 polypropylene sutures. The $\mathrm{CPB}$ and aortic cross-clamp times were $117 \mathrm{~min}$ and $60 \mathrm{~min}$ respectively. During this procedure no difficult bleeding encountered. There was no obvious abnormality in the function of artificial mechanical valves, and artificial ascending aortic blood flow was smooth, TEE suggested the aortic valve mechanical valve worked well, as shown in Fig. 3. Postoperative pathological indicated that the inner layer of the arterial wall was uneven, with partial fibrous hyperplasia, focal mucus degeneration, and a few lymphocytes infiltration. Immunohistochemical: smooth muscle cells were positive, CD3 + lymphocyte infiltration. Web dyeing:

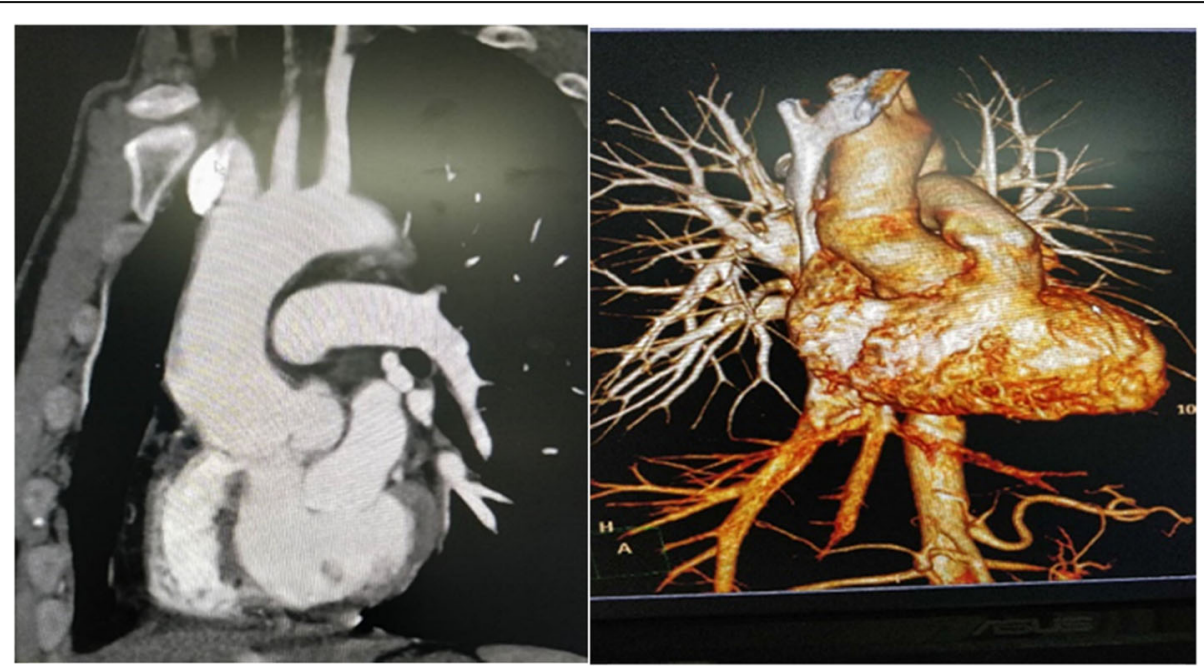

Fig. 2 CTA scan indicated the aortic sinus is cystic outwards 


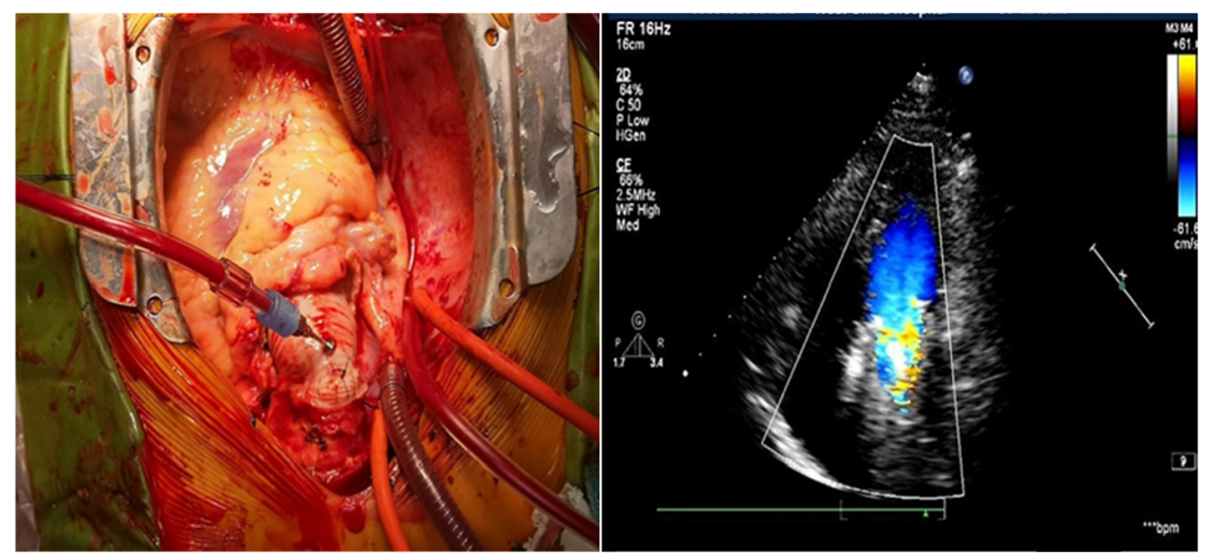

Fig. 3 TEE indicated that the aortic valve regurgitation disappeared

elastic fibers were positive, which suggested aseptic inflammatory changes in the aorta.

\section{Discussion}

BD is a chronic systemic inflammatory disease of unknown etiology. Clinical manifestations mainly include recurrent oral and genital diseases, skin ulcers, and so on [1]. The disease is distributed worldwide, but it presents an important regional difference in incidence rate. The Mediterranean, Middle East, and the Far East have the highest incidence rate, so it is also called "Silk Road disease." [2] The incidence rate in China is about $0.0001 \%$ $0.0004 \%$, mainly found in men between the ages of 20 and $40[3,4]$. The basic pathological manifestations are: nonspecific systemic vasculitis, including arteries and veins of any diameter, significant neutrophils and monocytes to infiltration, swelling of endothelial cells, and fibrin necrosis.

BD involves large arteries can lead to thromboses, occlusions and aneurysms [5], aneurysms rupture leads to death in most cases $[6,7]$, the main reasons including blood vessel inflammation and the nutrient vessels of the artery are damaged, which jointly damage to the arterial wall. BD also causes lesions in the aortic valves, results to aortic regurgitation because of vasculitis, which can be seen in5-19\% patients with BD [8]. BD involves coronary artery is very rare, only a few cases reported [9-11]. Saadoun. D reported a seven-year follow-up study of 817 patients found that male and arterial lesions were associated with increased mortality [12].

The treatment of BD including both drugs and surgery. Corticosteroid and immunosuppressive drugs have been widely used for $\mathrm{BD}$, and they are suggested before and after surgery because it will decrease the incidence of recurrent inflammation [13]. Anti-tumor necrosis factor agents, and interferon- $\alpha$ are also used for the treatment of BD recently [14]. Surgical treatment of aortic root involvement needs taking many factors into consideration, including surgical timing, procedure and materials, and perioperative management. The original Bentall procedure is used to repair aortic dissection which affecting the aortic root and valve, but it was related to the risk of false aneurysm formation and coronary separation, even re-operation $[15,16]$. Aortic valve replacement/repair (AVR) in BD requires more considerations for postoperative complications such as valve detachment and pseudoaneurysm formation, which are fatal sometimes. Major bleeding, PVL, detachment of the prosthetic valve, and Pseudoaneurysm formation after Bentall procedure or AVR are happened inevitably in most cases mainly because recurrent inflammation increase fragility of the aortic wall and aortic annular tissue, as well as reduction in prostacyclin production, besides, the nutrient vessels of the artery are also evolved by inflammation, both of which result to the injury of the arterial wall, so it is difficult to repair the aortic for pseudoaneurysm or hemorrhage at the needle eyes may form on the vessel wall after needle puncture.

To avoid valve detachment, many various technical modifications have been devised, including using a valved conduit or homograft, fix the prosthetic valve at the aortic annulus via buttress sutures, suture a belt-like Teflon felt on the lateral side to reinforce the valve, but both of those techniques have a common character that the valve or homograft is sutured directly on the aortic annulus or aortic wall, patients underwent those modifications also have an extremely poor prognosis. Ando, et al. [17] reported valve detachment happened after AVR in $36 \%$ of those with BD, in $20 \%$ patients who underwent valved conduit procedure. Kouchoukos, et al. [18] first described button Bentall procedure to prevent pseudo-aneurysm formation, it was more difficult and time consuming but was related to higher survival rate [16]. Ando, et al. [17, 19] reported their MBP that the aortic valve prosthesis was sutured into the graft at 1-2 
$\mathrm{cm}$ from the end of the graft via a continuous 3-0 polyester suture, so the composite graft was produced, then implanted into the aortic valve annulus use $2-0$ polyester buttressed mattress sutures, and place a circumferential belt-like felt outside the aortic wall. They used button technique to reconstruct the coronary arteries. No one of seven patients died during the follow-up 138 months.Okada [20] reported valve detachment happened in $1 / 8$ patients who underwent this modified Bentall technique. Chen and colleges [21] devised a modified Bentall procedure that they inserted A 6-F Foley catheter into the lumen of each coronary artery, under this Foley catheter guidewire, both coronary buttons were constructed with a 0.5 to $0.8 \mathrm{~cm}$ diameter cuff of the aortic wall and were mobilized over a short length to facilitate reimplantation. Excised the root totally, a valved conduit directly sutured to the left ventricular outflow tract instead of the fragile annulus to prevent recurrent prosthetic valve detachment in BD patients. They completed posterior half first, and then the coronary buttons were reimplanted to the valved conduit, without any tension during the whole process. at last, the distal end of the valved conduit was anastomosed to the distal ascending aorta. They used their Bentall procedure in $5 \mathrm{BD}$ patients with postoperative aortic prosthetic valve detachment and achieved satisfactory short-term and mid-term results. MBP have many advantages than the normal Bentall procedure, such as MBP can reduce major bleeding risk, prevent coronary arteries from kinking, decrease tension on button coronary anastomosis, avoid false aneurysms development, reduce operative time, and lower morbidity and mortality rate.

Nowadays, although many new surgical techniques have been used, it seems that valve detachment and pseudoaneurysm formation are not avoidable. Fortunately, there are more and more reported cases indicate it is beneficial for $\mathrm{BD}$ patient to control inflammatory activity by corticosteroids and immunosuppressive drugs, before and after the procedure, CRP is usually recommended as a standard biomarker to evaluate rheumatic activity.

\section{Conclusion}

we report a patient of BD combined with severe aortic valve regurgitation and two giant pseudoaneurysms of the aortic sinus. Preoperative used of corticosteroids and immunosuppressants until the inflammatory markers were diminished and then the modified Bentall procedure was successfully performed to replace the aortic root, used corticosteroids and immunosuppressants after surgery in order to decrease the recurrent incidence of aneurysm, Hatemi $\mathrm{G}$ and Balcioglu $\mathrm{O}[22,23]$ recommended medical treatment at least 2 years is effective, our patient recovered well after 8 months follow up.

\section{Abbreviations}

AVR: Aortic valve replacement; BD: Behcet's disease; CPB: Cardiopulmonary bypass; CT: Computed tomography; MBP: Modified Bentall procedure; PVL: Perivalvular leaks; TTE: Transthoracic echocardiography

\section{Acknowledgements \\ Not applicable.}

\section{Authors' contributions}

ZF K participated in the surgery procedure and performed the CT scan, YP J analyzed and interpreted the patient data regarding Bechet's disease. ZY C performed the statistical analysis and drafted the manuscript, YQ G designed the study and revised this manuscript. All authors read and approved the final manuscript.

\section{Funding}

1. The article is supported by National Natural Science Foundation of China (No.81470481);

2. 1.3.5 project for disciplines of excellence, West China Hospital, Sichuan University.

\section{Availability of data and materials}

The dataset of this case report is available from the corresponding author on reasonable request.

Ethics approval and consent to participate

The hospital ethics committee approval was granted of this case report.

\section{Consent for publication}

Written informed consent was obtained from the patient for publication of this case report and any accompanying images. A copy of the written consent is available for review by the Editor-in-Chief of this journal.

\section{Competing interests}

The authors declare that they have no competing interests.

Received: 5 November 2019 Accepted: 7 January 2020

Published online: 29 January 2020

\section{References}

1. Sakane T, Takeno M, Suzuki N, et al. Behcet's disease. N Engl J Med. 1999:341:1284-91.

2. Levine JA, O'Duffy JD. Pseudo-Behçet's syndrome-a description of twentythree cases. France: Elsevier Science Publishers; 1993. p. 295-8.

3. Davatchi F, Chams-Davatchi C, Shams H, et al. Behcet's disease: epidemiology, clinical manifestations, and diagnosis. Expert Rev Clin Immunol. 2017;13(1):57-65

4. Tohmé A, Aoun N, El-Rassi B, et al. Vascular manifestations of Behçet's disease. Eighteen cases among 140 patients. Joint Bone Spine. 2003;70(5): 384-9 PMid:14563470.

5. Nair JR, Moots RJ. Behcet's disease. Clin Med (Lond). 2017;17(1):71-7.

6. Kwon Koo B, Shim WH, Yoon YS, et al. Endovascular therapy combined with immunosuppressive treatment for pseudoaneurysms in patients with Behçet's disease. J Endovasc Ther. 2003;10(1):75-80.

7. Ohira S, Masuda S, Matsushita T. Nine-year experience of recurrent anastomotic pseudoaneurysms after thoracoabdominal aneurysm graft replacement in a patient with Behçet disease. Heart Lung Circ. 2014;23(10): e210-3.

8. Gonzalez T, Hernandez-Beriain JA, Rodriguez-Lozano B, et al. Severe aortic regurgitation in Behget's disease. J Rheumatol. 1993;20:1807-8.

9. Kaseda S, Koiwaya Y, Tajimi T, et al. Huge false aneurysm due to rupture of the right coronary artery in Behcet's syndrome. Am Heart J. 1982;103:569-71.

10. Bowles CA, Nelson AM, Hammill SC, et al. Cardiac involvement in Behcet's disease. Arthritis Rheum. 1985:28:345-8.

11. Schiff S, Moffatt R, Mandel WJ, et al. Acute myocardial infarction and recurrent ventricular arrhythmias in Behget's syndrome. Am Heart J. 1982;103:438-40.

12. Saadoun D, Wechsler B, Desseaux K, et al. Mortality in Behçet's disease. Arthritis Rheum. 2010;62(9):2806-12. 
13. Liu Q, Ye W, Liu C, et al. Outcome of vascular intervention and use of perioperative medications for nonpulmonary aneurysms in Behce't disease. Surgery. 2016;159:1422-9.

14. Chan E, Sangle SR, Coghlan JG, et al. Pulmonary artery aneurysms in Behcet's disease treated with anti-TNFa: a case series and review of the literature. Autoimmun Rev. 2016;15:375-8.

15. Kouchoukos NT, Wareing TH, Murphy SF, et al. Sixteen-year experience with aortic root replacement. Results of 172 operations. Ann Surg. 1991;214(3):308.

16. Marvasti M, Parker F Jr, Randall P, et al. Composite graft replacement of the ascending aorta and aortic valve. Late follow-up with intra-arterial digital subtraction angiography. J Thorac Cardiovasc Surg. 1988;95(5):924-8.

17. Ando M, Sasako Y, Okita Y, et al. Valved conduit operation for aortic regurgitation associated with Behcet's disease. Jpn J Thorac Cardiovasc Surg. 2000;48:424-7.

18. Kouchoukos N, Karp R. Resection of ascending aortic aneurysm and replacement of aortic valve. J Thorac Cardiovasc Surg. 1981;81(1):142-3.

19. Ando M, Okita Y, Sasako $Y$, et al. Surgery for aortic regurgitation caused by Behcet's disease: aclinical study of 11 patients. J Card Surg. 1999;14:116-21.

20. Okada K, Eishi K, Takamoto S, et al. Surgical management of Behcet's aortitis: a report of eight patients. Ann Thorac Surg. 1997;64:116-9.

21. Chen LW, Wu XJ, Cao H, et al. Valved conduit attached to left ventricular outflow tract for valve detachment in Behçet's disease. Ann Thorac Surg. 2017;103(3):e301-20.

22. Hatemi $G$, Silman $A$, Bang $D$, et al. EULAR recommendations for the management of Behcet's disease. Ann Rheum Dis. 2008;67:1656-62.

23. Balcioglu O, Ertugay S, Bozkaya $\mathrm{H}$, et al. Endovascular repair and adjunctive immunosuppressive therapy of aortic involvement in Behçet's disease. Eur J Vasc Endovasc Surg. 2015;50:593-8.

\section{Publisher's Note}

Springer Nature remains neutral with regard to jurisdictional claims in published maps and institutional affiliations.

Ready to submit your research? Choose BMC and benefit from:

- fast, convenient online submission

- thorough peer review by experienced researchers in your field

- rapid publication on acceptance

- support for research data, including large and complex data types

- gold Open Access which fosters wider collaboration and increased citations

- maximum visibility for your research: over $100 \mathrm{M}$ website views per year

At $\mathrm{BMC}$, research is always in progress.

Learn more biomedcentral.com/submissions 